\title{
The relationship between polar mesospheric clouds and their background atmosphere as observed by Odin-SMR and Odin-OSIRIS
}

\author{
Ole Martin Christensen ${ }^{1,2}$, Susanne Benze ${ }^{2}$, Patrick Eriksson ${ }^{1}$, Jörg Gumbel ${ }^{2}$, Linda Megner ${ }^{2}$, and Donal P. Murtagh \\ ${ }^{1}$ Department of Earth and Space Sciences, Chalmers University of Technology, Gothenburg 41296, Sweden \\ ${ }^{2}$ Department of Meteorology, Stockholm University, Stockholm 11296, Sweden
}

Correspondence to: Ole Martin Christensen (olemartin.christensen@misu.su.se)

Received: 29 March 2016 - Published in Atmos. Chem. Phys. Discuss.: 28 April 2016

Revised: 9 September 2016 - Accepted: 19 September 2016 - Published: 10 October 2016

\begin{abstract}
In this study the properties of polar mesospheric clouds (PMCs) and the background atmosphere in which they exist are studied using measurements from two instruments, OSIRIS and SMR, on board the Odin satellite. The data comes from a set of tomographic measurements conducted by the satellite during 2010 and 2011. The expected ice mass density and cloud frequency for conditions of thermodynamic equilibrium, calculated using the temperature and water vapour as measured by SMR, are compared to the ice mass density and cloud frequency as measured by OSIRIS. We find that assuming thermodynamic equilibrium reproduces the seasonal, latitudinal and vertical variations in ice mass density and cloud frequency, but with a high bias of a factor of 2 in ice mass density.

To investigate this bias, we use a simple ice particle growth model to estimate the time it would take for the observed clouds to sublimate completely and the time it takes for these clouds to reform. We find a difference in the median sublimation time $(1.8 \mathrm{~h})$ and the reformation time $(3.2 \mathrm{~h})$ at peak cloud altitudes $(82-84 \mathrm{~km})$. This difference implies that temperature variations on these timescales have a tendency to reduce the ice content of the clouds, possibly explaining the high bias of the equilibrium model.

Finally, we detect and are, for the first time, able to positively identify cloud features with horizontal scales of 100 to $300 \mathrm{~km}$ extending far below the region of supersaturation $(>2 \mathrm{~km}$ ). Using the growth model, we conclude these features cannot be explained by sedimentation alone and suggest that these events may be an indication of strong vertical transport.
\end{abstract}

\section{Introduction}

Noctilucent or polar mesospheric clouds (PMCs) are clouds that form just below the polar summer mesopause, due to the extremely cold conditions in this region. During the last decades there has been a considerable effort to understand the composition and formation processes of these clouds, and several key features have been discovered. We know that they consist of ice particles (Hervig et al., 2001) with radii around $50 \mathrm{~nm}$ (e.g. Thomas and McKay, 1985; Baumgarten et al., 2007). After their formation, the ice particles sediment downwards, growing into visible particles while they consume the available water from the ambient atmosphere (e.g. Jensen and Thomas, 1988; von Zahn and Berger, 2003).

These clouds are very sensitive to changes in the atmosphere and, as such, serve as a useful tool to investigate this otherwise hard-to-reach region of the atmosphere. $\mathrm{Ob}$ servations of PMCs have been used to establish connections between the winter and summer hemispheres (interhemispheric coupling) (Becker et al., 2004; Karlsson et al., 2007), as well as between different atmospheric layers (intrahemispheric coupling) (Karlsson et al., 2009). Furthermore, PMCs are considered to be an indicator of long-term changes in the background atmosphere (Thomas et al., 1989; Hervig and Stevens, 2014), hence PMC measurements can help to establish trends in temperature and water vapour in the mesopause region where they form (Hervig et al., 2016).

For PMCs to form, the atmospheric conditions must be favourable. Berger and von Zahn (2007) show that cloud nucleation occurs most effectively in regions where the concentration of water vapour exceeds the saturation level by a 
factor of 10 or more, with the majority of the particles in clouds located at $69^{\circ} \mathrm{N}$, nucleating about $3 \mathrm{~km}$ higher and $9^{\circ}$ polewards of the observed clouds. This means that ice particles are transported in the atmosphere, but at a variety of different background conditions before finally growing into visible clouds. Following trajectories of single ice particles models, Megner (2011) and Kiliani et al. (2013) have shown that cloud growth occurs in bursts, in regions with high supersaturation near the bottom of the clouds, with most of the rapid growth occurring less than $3 \mathrm{~h}$ before observation.

Since cloud growth and sublimation occur over such short timescales and are so dependent on the saturation ratio, measurements of temperature, water vapour concentration and cloud properties should ideally be performed simultaneously. Such studies have been carried out using the Solar Occultation For Ice Experiment (SOFIE) on the Aeronomy of Ice in the Mesosphere (AIM) satellite. These have shown that many of the critical cloud parameters, in particular cloud frequency and the integrated ice column can be successfully recreated on a seasonal basis by employing a 0 -D model assuming thermodynamic equilibrium (Hervig et al., 2009b, 2013). Other such studies include Zasetsky et al. (2009) who used measurements of temperature, water vapour and PMCs from the Atmospheric Chemistry Experiment Fourier transform spectrometer (ACE-FTS) combined with a nucleation model to determine the equilibrium sizes of the measured ice particles.

Both SOFIE and ACE-FTS perform measurements using solar occultation; this results in measurements at only one or two latitudes during an orbit. This means that horizontal structures in the clouds are not resolved by these instruments. Furthermore, due to their limb-sounding geometry, clouds closer to and further away from the satellite than the tangent point will appear to be at lower tangent altitudes than their true altitudes (Hervig et al., 2009a; Eremenko et al., 2005). This means that these instruments must filter out low-lying clouds, reducing their ability to investigate the lower edge of the cloud layer.

In this paper we investigate the relationship between polar mesospheric clouds and their immediate surrounding atmosphere using a simple model assuming thermodynamic equilibrium. Furthermore, we determine how far individual cloud pixels are from thermal equilibrium using a growth model similar to Zasetsky et al. (2009). Determining the time to reach equilibrium is interesting as it provides information on at what timescales PMCs respond to changes in the background atmosphere, and hence at what timescales a simple thermodynamic equilibrium model can be expected to provide reasonable results. Finally, since these deviations from equilibrium can be caused by variability in the background atmosphere, quantifying them can provide metrics useful for testing to what degree models capture this variability.

The analysis is performed on a set of measurements performed by the Odin satellite during 2010 and 2011. These measurements were specifically designed to target the summer mesopause region, and allows us to investigate both hori- zontal and vertical structures in both the clouds and the background atmosphere. The measurements are retrieved using a tomographic approach. This means that the information gained by measuring the same area of the atmosphere from different directions is used in order to better determine inhomogeneities along the line of sight of the instrument. In particular, the tomographic approach allows us to separate lowaltitude clouds from near and far-field clouds, for the first time providing simultaneous observations of these low-lying clouds and their background atmospheric conditions.

\section{Method}

\subsection{Odin satellite}

Odin is a satellite operating in sun-synchronous orbit with an inclination of $98^{\circ}$ and with an ascending node equator crossing time of 18.00. It was launched in 2001 and carries two instruments on board, the Optical Spectrograph and Infrared Imager System (OSIRIS) and the sub-millimetre radiometer (SMR). The two instruments are near perfectly coaligned and, as such, perform measurements at the same time and place. The main difference is the across-track horizontal field of view of the two instruments. SMR has a resolution of $2.5 \mathrm{~km}$ across-track, while OSIRIS covers $20 \mathrm{~km}$ across track.

During the summer of 2010 and 2011, a special set of measurements focusing only on the regions around PMCs were performed, measuring at tangent altitudes between 75 and $90 \mathrm{~km}$. Measuring only at these limited tangent altitudes increases the horizontal sampling compared to nominal Odin measurements. This increase in horizontal sampling in turn allows for tomographic retrievals, further increasing the spatial resolution and information content that can be retrieved. The retrievals are performed on each instrument separately before combining the retrieved data. To take into account thermal twisting in the satellite frame occurring during the summer season (McLinden et al., 2007), the altitude of the OSIRIS data is adjusted upwards $580 \mathrm{~m}$ before the two data sets are merged. The remaining collocation error is less than $100 \mathrm{~m}$ at the tangent point, which is less than the vertical and horizontal resolution of the two instruments (private correspondence with Nick Lloyd).

\subsubsection{SMR}

SMR measures the $\mathrm{H}_{2} \mathrm{O}$ emission line at $557 \mathrm{GHz}$ and can retrieve the water vapour concentration and temperature across the entire middle atmosphere (e.g. Urban et al., 2007; Lossow et al., 2009). The tomographic measurements are used to retrieve water vapour and temperature between 75 and $90 \mathrm{~km}$ with a vertical resolution of $2.5 \mathrm{~km}$, a horizontal resolution of $200 \mathrm{~km}$ and a precision of $0.2 \mathrm{ppmv}$ for water vapour and $2 \mathrm{~K}$ for temperature (Christensen et al., 2015). The tomographic SMR measurements are performed using two different in- 
strument configurations called frequency mode 13 and 19. It has been shown that there is a systematic difference in the retrieved water vapour and temperature between these two modes, and following the recommendations of Christensen et al. (2015), we will only use the results from frequency mode 13 in this study, which is the mode most consistent with measurements by AIM-SOFIE and ACE-FTS (within $5 \mathrm{~K}$ and $20 \%$ of water vapour volume mixing ratio). This data is available for 15-16 July and 12-13 August for 2010, and 16-17 June and 18-19 July for 2011.

\subsubsection{OSIRIS}

OSIRIS tomographic measurements are used to retrieve the local cloud-scattering coefficient between 78 and $87 \mathrm{~km}$. The measurements have the possibility of retrieving cloud structures with a horizontal extent of $\sim 200 \mathrm{~km}$ and a vertical extent of $1 \mathrm{~km}$. The tomographic algorithm used to convert limb-integrated atmospheric line-of-sight radiances into local information of cloud-scattering coefficient is discussed in detail by Hultgren et al. (2013). Observations of the local scattering coefficient at seven UV wavelengths (277.3, 283.5, $287.8,291.2,294.4,300.2,304.3 \mathrm{~nm}$ ) enable the retrieval of ice particle mode radius, number density and ice mass density. For the retrieval of mode radius, assumptions need to be made concerning the particle population. Consistent with earlier studies (Hervig et al., 2009a; Baumgarten et al., 2010; Lumpe et al., 2013), we make the following assumptions.

- Gaussian distribution of particle sizes with a distribution width that varies as $0.39 \times$ mode radius but stays fixed at $15.8 \mathrm{~nm}$ for mean radii greater than $40 \mathrm{~nm}$.

- Particles are randomly oriented oblate spheroids with an axial ratio of 2 .

The PMC microphysical retrieval and resulting uncertainties in cloud-scattering coefficient and microphysical products are described in detail by Hultgren and Gumbel (2014). To summarise, the ice mass density is retrieved with an accuracy of around $5 \mathrm{ng} \mathrm{m}^{-3}$ and the mode radius is retrieved with an accuracy of $10 \mathrm{~nm}$. These estimates do not include errors resulting from the assumptions in the particle size distribution.

For the first time, the current study shows OSIRIS tomographic results from the Northern Hemisphere PMC season of 2011. This season was not included by Hultgren et al. (2013) and Hultgren and Gumbel (2014) due to retrieval stability issues for this season, which resulted in unphysical variations of the cloud-scattering coefficient with wavelength. This artefact was found to be related to an error in the background subtraction at lower latitudes, resulting in negative radiances from the modelled atmosphere. By not allowing the background subtraction to exceed the measured limb radiance, useful data could be retrieved from 36 of the 89 of the orbits from 2011.
In total, there are 35 tomographic orbits available that provide both SMR data in frequency mode 13 and usable OSIRIS data. Of these, 11 orbits are from July 2010, 12 from August 2010, 4 from June 2011 and 8 from July 2011. Due to the few orbits available from June, only data results from July and August will be shown in this paper when discussing seasonal differences in the data.

\subsection{The thermodynamic model}

In order to quantitatively compare the background atmosphere measured by SMR to the cloud properties measured by OSIRIS, we use a simple model which predicts the expected ice mass density from the observed background atmosphere by simply assuming thermodynamic equilibrium. Similar models have successfully been used in previous studies (e.g. Russell et al., 2010; Rong et al., 2012) to investigate the relationship between PMCs and the background atmosphere. For the study presented in this paper, the main advantage of such a simple model is that is directly maps the atmosphere observed by SMR into ice mass, without requiring any further assumptions. Furthermore, to estimate the time it would take the observed cloud pixels to reach thermodynamic equilibrium, a growth model is used. Both these models are introduced in this section.

\subsubsection{Growth model}

For clouds to form in the atmosphere, the partial pressure of water vapour needs to exceed the saturation vapour pressure. Several expressions have been used to calculate the saturation pressure for water vapour over ice under mesospheric conditions (see e.g. Rapp and Thomas, 2006), and in this study we will use the formula from Murphy and Koop (2005), which is derived from a numerical integration of the Clausius-Clapeyron equation. The saturation pressure is then given by

$$
\begin{aligned}
& P_{\text {sat }}=\exp \left(9.550426-\frac{5723.265}{T}+3.53068 \cdot \ln (T)\right. \\
& -0.00728332 \cdot T),
\end{aligned}
$$

where $T$ is the ambient temperature. If the mixing ratio of water vapour is given by $Q_{\text {gas }}$ and the mixing ratio of ice (defined as the ratio of water molecules in ice phase to the total number of molecules in the atmosphere) is given by $Q_{\text {ice }}$, the total water pressure is

$P_{\text {tot }}=P_{\text {gas }}+P_{\text {ice }}=\left(Q_{\text {gas }}+Q_{\text {ice }}\right) \cdot p$,

where $p$ is the ambient pressure. In this study $T$ and $Q_{\text {gas }}$ are taken from the SMR measurements and $Q_{\text {ice }}$ from OSIRIS. The pressure is taken from the MSISE-90 model (Hedin, 1991).

In general clouds will grow if the supersaturation ratio $S \equiv$ $\frac{P_{\text {gas }}}{P_{\text {sat }}}$ is greater than one, and sublimate if the opposite is the 
case. Hesstvedt (1961) estimated the growth rate of single ice particles as

$$
\frac{\mathrm{d} r}{\mathrm{~d} t}=\frac{f}{\rho_{\text {ice }}} \sqrt{\frac{m_{\mathrm{H}_{2} \mathrm{O}}}{2 \pi R T}} \cdot\left(P_{\text {gas }}-P_{\text {sat }}\right) \cdot \Phi,
$$

where $r$ is the radius of the ice particle, $\rho_{\text {ice }}$ the density of ice, $m_{\mathrm{H}_{2} \mathrm{O}}$ the molar mass of water, $R$ the molecular gas constant, and $f$ is a sticking parameter which we set to 0.83 following Gadsden (1998). Finally, since the growth/sublimation rate of a particle is proportional to its surface area, a factor $\Phi$, defined as the ratio between the surface area of a non-spherical particle to that of a volume equivalent sphere, is included (Turco et al., 1982). For spheroids with an axial ratio of 2 , $\Phi=1.095444$. If $P_{\text {gas }}$ and $P_{\text {sat }}$ are known, Eq. (3) can be numerically integrated for each ice particle to determine $r(t)$. Assuming that the total water content is conserved, the time to reach equilibrium size and the time to sublimate $(r(t)=0)$ can be estimated for single ice particles.

PMCs consist not of a single particle, but an ensemble of particles. However, the exact size distribution for PMC particles is highly uncertain. Thus, for simplicity, the particles are assumed to all be spheroids with the same radius and with an axial ratio of 2 . The radius used is the corresponding mode radius retrieved from OSIRIS, and the number of particles is then determined by ensuring that the ice mass density was equal to the ice mass density retrieved from OSIRIS. This single radius particle size distribution differs from the Gaussian size distribution used in the OSIRIS retrievals. However, since Eq. (3) is independent of radius, the particle size distribution will not change with time since all particles grow with the same speed. This means that the time it takes for a single radius size distribution to grow to equilibrium is equal to that of a Gaussian. This does not necessarily hold for sublimating clouds, as the smallest particles in the Gaussian distribution sublimate completely. However, once this stage is reached, the total ice remaining in the cloud parcel is negligible, thus this effect will not significantly impact the results presented in this paper.

Furthermore, the growth model presented does not take into account the fact that forming ice on a spherical surface (i.e. small particles) requires more energy than on flat surfaces. This is known as the Kelvin effect and can be accounted for by adjusting the saturation pressure according to the following:

$P_{\text {sat }}(r)=p_{\text {sat }}(\infty) \cdot \exp ^{2 m \sigma / \rho k T r_{\mathrm{n}}}$,

where $P_{\text {sat }}(\infty)$ is the vapour pressure above a flat surface (i.e. Eq. 1), $m$ the molecular weight of water, $\sigma$ the surface free energy $\left(0.122 \mathrm{~J} \mathrm{~m}^{-2}\right), \rho$ the density of the ice particle, $k$ the Boltzmann constant and $r_{\mathrm{n}}$ the radius of the nucleation kernel. Since OSIRIS cannot measure particles of the size where this term becomes important, the Kelvin effect will generally not be used in this study. We will only use it in the discussion of reformation of clouds in Sect. 4.

\subsubsection{Equilibrium model}

With enough time, the amount of ice in an air parcel will reach thermodynamic equilibrium; in this case the ice mass density is given by

$m_{\text {ice }}=\left(P_{\text {tot }}-P_{\text {sat }}\right) \frac{m_{\mathrm{H}_{2} \mathrm{O}}}{R \cdot T}$.

This value will be referred to as the ice mass density in equilibrium or simply "the equilibrium model". When this level is reached, all the excess water has been converted into ice, and the saturation ratio of the atmosphere is 1 . This is rarely the case in the real atmosphere, and assuming thermodynamic equilibrium has been shown to overestimate the ice mass density to a varying degree. Hervig et al. (2009b) found a better agreement between measurements and the equilibrium model by replacing $P_{\text {tot }}$ with $P_{\text {gas }}$ in Eq. (5) and, with this assumption, the model produced $\sim 35 \%$ more ice than found in the measurements. In more recent studies using updated SOFIE data, the high bias of the model is significantly reduced with Hervig et al. (2015) indicating a high bias of only $10 \%$ in the Northern Hemisphere. Using data from Aura-MLS, Rong et al. (2014) found that the overestimation changes depending on the time of the season, and introduced an additional scaling factor $F$ ranging from 0 to 1 to reduce the ice mass in the model, in particular late in the season.

In this paper we will use the equilibrium model directly (i.e. using $P_{\text {tot }}$ without any scaling factors), and only include results using the model from Hervig et al. (2009b) (i.e. $P_{\text {gas }}$ ) in Sect. 3.2 to contextualise the results presented.

\section{Results}

\subsection{OSIRIS clouds and background atmosphere}

A first step in relating the presence of clouds as measured by OSIRIS with their immediate background atmosphere is to look at the deviation from the mean background atmosphere in areas where clouds are detected. This is done by identifying all pixels in the OSIRIS measurements where an ice mass density $>0 \mathrm{ng} \mathrm{m}^{-3}$ is retrieved. The zonal mean background atmosphere with and without clouds is then calculated. The difference between these atmospheric fields can be ascribed to the presence of clouds. These anomaly fields are then averaged across all latitudes to a mean anomaly profile. Using this method (i.e. first calculating the zonal mean anomalies) has the advantage that it takes into account the latitudinal distribution of clouds, whereas simply taking the difference of cloud and cloud-free pixels would result in profiles weighted towards higher/lower latitudes for cloud/cloud-free conditions. To provide context for these anomaly profiles the mean background is added and the results for the July and August data are shown in Fig. 1. 

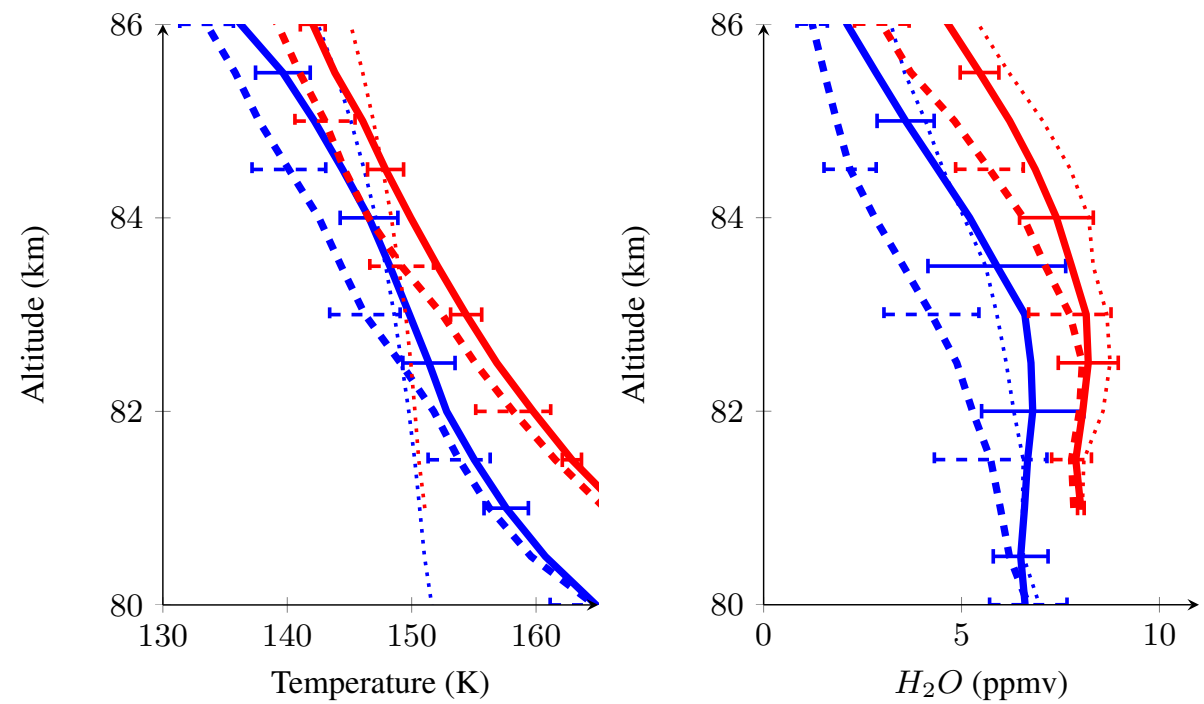

Figure 1. The figure shows differences in the measured background temperature and water vapour concentration for cloud (dashed lines) and cloud-free pixels (solid lines) for July (blue) and August (red). The values are calculated by adding the measured mean profile for latitudes $>70^{\circ} \mathrm{N}$ to the mean anomalies from these latitudes (for further description see the text). The thin horizontal lines are the standard deviation for the plotted quantities. The thin dotted lines show the mean frost point temperature (left figure) and total water content for cloudy pixels $\left(Q_{\text {tot }}=Q_{\text {gas }}+Q_{\text {ice }}\right)$ (right figure).

In general, the atmosphere is about $3-4 \mathrm{~K}$ cooler when clouds are observed, with a smaller difference in temperature at lower altitudes. A clear depletion of water vapour (12 ppmv) can be seen with the strongest effect in the middle of the PMC layer at about $83 \mathrm{~km}$ in July and $85 \mathrm{~km}$ in August. The background water vapour (no clouds) and the total water content for pixels with clouds (ice + vapour) are similar in July, while in the August data the pixels with clouds show a slightly elevated total water content compared to the pixels without clouds. The fact that total water content is preserved in the core cloud altitude region (82-84 km) in July indicates that the growth from subvisible to visible clouds occurs locally, thus water vapour is transformed into ice when conditions allow it. On the contrary, in August, where enhanced total water content is observed, the water in the clouds is not simply depleted from the local surroundings of the clouds, but rather from other areas of the atmosphere. This may be due to long formation times at the highest altitudes, or an indication that the clouds/background atmosphere have undergone transport separating the two.

It should be noted that Fig. 1 shows no sign of direct water vapour enhancement under the areas where clouds are detected. The reason for this is that clouds are identified on a pixel by pixel basis, hence enhancement below a cloud layer is considered to be cloud-free in the analysis. However, looking at single orbits (see Sect. 3.4) water vapour concentrations above $10 \mathrm{ppmv}$ can be seen between 80 and $82 \mathrm{~km}$ both below detected clouds as well as in areas without clouds directly above them. This highlights the fact that, due to atmo- spheric variability, water vapour enhancements can persist even after clouds have sublimated.

To further investigate whether a systematic enhancement is seen in the data, zonal averages of water vapour were made for profiles with a vertically integrated ice content greater than $5 \mathrm{~g} \mathrm{~km}^{-2}$, and a zonal mean for those with less integrated ice content. Comparing the two, we find indications of systematic water vapour enhancements at some latitudes and times; however these results are not consistent across the data set. This is unlike Hervig et al. (2015) who find a more consistent pattern of hydration below clouds. This discrepancy is most likely due to the fact that establishing the correct unperturbed background atmosphere is hard to achieve with the limited data provided by the tomographic data set.

\subsection{Water vapour and ice budget}

Polar mesospheric clouds are highly sensitive to their background atmosphere, and small errors in the measured temperature or water vapour concentrations used in the calculations described in Sect. 2.2 can give large errors in the equilibrium ice content as well as growth and sublimation times. Thus, before using the data to look at individual measurements, we investigate the ability of the data to reproduce the expected large-scale properties of the ice distribution.

The amount of ice expected in thermodynamic equilibrium can be compared to the ice retrieved from OSIRIS measurements. To take into account the sensitivity of the OSIRIS measurements, the ice mass density in pixels with ice mass density below a certain threshold is set to 0 for both the OSIRIS and model data. The scattering coefficient measured 
depends on the size and number of ice particles in the cloud, as well as the scattering angle which varies between 70 and $90^{\circ}$ for OSIRIS. A reasonable threshold was hence determined by estimating the average ice mass density (all clouds, all scattering angles) needed to reach a cloud-scattering coefficient of $2 \times 10^{-9} \mathrm{~m}^{-1} \mathrm{str}^{-1}$ at $83 \mathrm{~km}$. This results in a value of $10.08 \mathrm{ng} \mathrm{m}^{-3}$ so for simplicity the threshold is set to $10 \mathrm{ng} \mathrm{m}^{-3}$. The OSIRIS data are also filtered using the same method to ensure that the two data sets are consistent.

\subsubsection{Vertical comparison}

Figure 2 depicts the overall ice distribution (mean of June, July and August data) at different altitudes. The left figure shows the mean ice mass density while the right shows cloud presence. We find that assuming thermodynamic equilibrium overestimates the ice mass roughly by a factor of 2 across the entire region. This indicates that the whole measured region is, on average, highly supersaturated, with supersaturation ratios greater than 100 often occurring above $84 \mathrm{~km}$. Even in areas where clouds are measured, a considerable supersaturation $(S>10)$ is observed.

Replacing $P_{\text {tot }}$ with $P_{\text {gas }}$ in Eq. (5), as in Hervig et al. (2009b), reduces the difference between the retrieved ice mass density and the one predicted by the equilibrium model, especially around the peak ice mass density. However, the discrepancy still remains, in particular at the highest altitudes.

Looking at the cloud presence, which we define as the frequency of the number of pixels with an ice mass density above the aforementioned detection threshold, the agreement between the model and the measurements is better than for ice mass density, at least up to $83 \mathrm{~km}$. This indicates that it is the strength of the clouds, rather than the frequency, that leads to the excess mass in the equilibrium model. Using $P_{\text {gas }}$ as an input, the agreement in cloud frequency between the model and the measurements is improved further, agreeing up to $84 \mathrm{~km}$.

In the OSIRIS data a large difference in cloud presence is seen between July and August, with a presence at the peak of $40 \%$ in July and $18 \%$ in August. This difference is significantly less in the equilibrium model where the cloud presence in July is 60 and $50 \%$ in August. However, in both the measurements and the model the peak presence altitude is about $1 \mathrm{~km}$ higher in August than in July.

\subsubsection{Comparison of zonal means}

Cloud cover varies with latitude, with higher cloud coverage at higher latitudes than at lower. In Fig. 3 the ice column (integrated ice mass density across all altitudes) and cloud frequency (the percentage of times a cloud pixel with a ice mass density over the given threshold is present at any altitude) are shown for both the OSIRIS measurements and the equilibrium model. The latitudinal variations in the ice column are captured quite well by the model, with more ice polewards than at lower latitudes and more during July compared to August. Looking at the cloud frequency, however, an interesting discrepancy is visible in the July data: while there are plenty of clouds in the model all the way down to $70^{\circ} \mathrm{N}$, the observations show a clear reduction of cloud frequency with latitude. This indicates that at lower latitudes the equilibrium model produces many thin clouds which are not measured by OSIRIS. Possible reasons for this are discussed in Sect. 4.

Overall we find that the equilibrium model overestimates ice mass by a factor of $\sim 2\left(\sim 1.6\right.$ when $P_{\text {gas }}$ is used $)$, and the overestimation is larger late in the season than in the middle. The position of the peak ice mass density is reproduced at the same altitude as the measurement and the seasonal variation is seen with a higher ice mass density peak in August compared to July. The latitudinal variation of the integrated water content is also seen in both the equilibrium model and the measurements, while the cloud frequency in the model shows less latitudinal variation than in the measurements, in particular in July.

\subsubsection{Sensitivity analysis}

The overestimation of ice in the equilibrium model is consistent with results from Rong et al. (2014) and Hervig et al. (2009b), but in disagreement with more current studies using the SOFIE data (Hervig et al., 2013, 2015), which show a significantly lower bias $(0-10 \%)$. The reason for this disagreement is not clear, and to investigate this further, the sensitivity of the model to biases in the input data was tested. The grey lines in Fig. 2 include the ice mass density calculated from all SMR measurements with an assumed systematic error of $\pm 5 \mathrm{~K}$ and $\pm 20 \%$ water vapour concentration.

Figure 2 shows that even a small systematic bias in the temperature retrieved from SMR measurements would result in a large discrepancy between the modelled cloud frequencies and those observed by OSIRIS. Hence, although a temperature bias in the SMR data would explain the discrepancy in ice mass between the model and observations, this would imply that PMCs on average largely exist outside the region of supersaturation, which would contradict all of the previously mentioned studies.

Reducing the water vapour concentration used as input in the model has a less drastic effect, and reduces the modelled ice mass while maintaining the cloud presence at levels similar to that observed by OSIRIS. Although Christensen et al. (2015) found no such bias in the average water vapour retrieved by SMR compared to the SOFIE (V1.2) or ACE-FTS (V3.5) data, Hervig et al. $(2013,2015)$ uses an estimated background water vapour profile based on an non-cloud average over several days, which may lead to differences compared to the results shown in Fig. 2. Finally, differences in resolution, measurement geometries, latitudinal and spatial sampling, as well as the differences in sensitivity of OSIRIS 

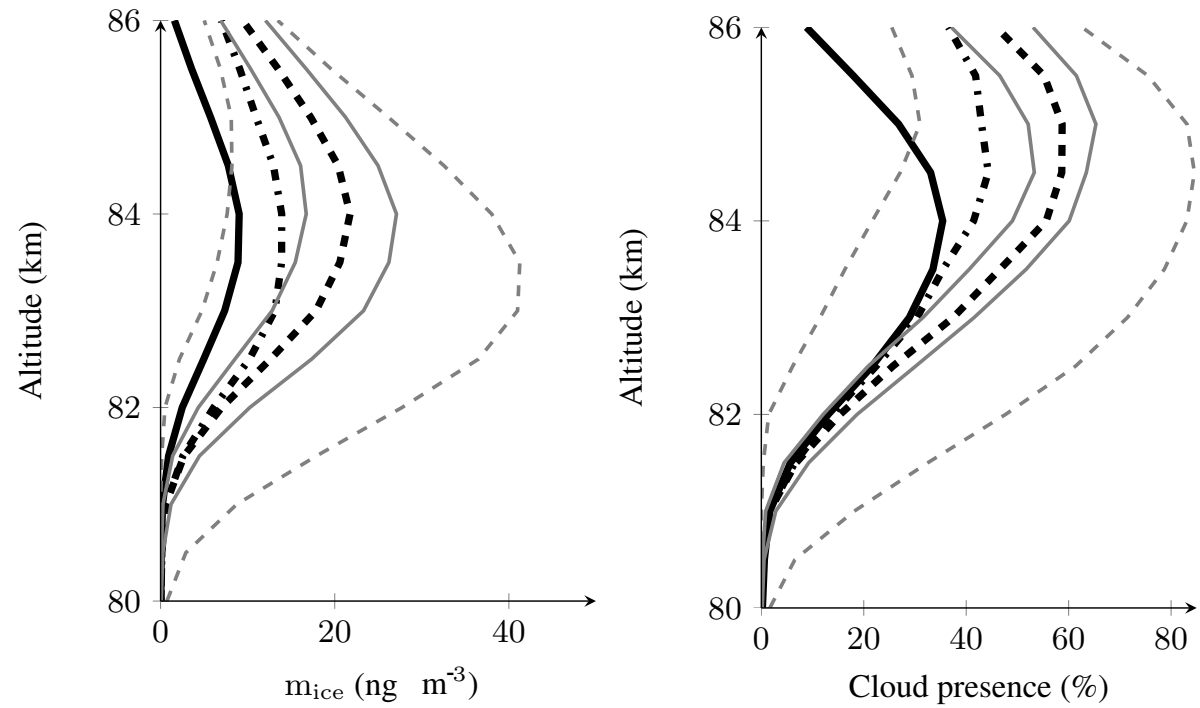

Figure 2. Cloud properties in equilibrium with the atmosphere measured by SMR compared to the OSIRIS measurements. The left plot shows the ice mass density inferred from SMR and OSIRIS according to Eq. (5) (black dashed) and the result if only $P_{\text {gas }}$ is used in Eq. (5) (black dotted/dashed). The black solid line shows the ice mass density measured by OSIRIS. The right plot shows the cloud presence for the same data. The thin grey lines are the results if the calculations using $P_{\text {tot }}$ are carried out with a modified atmosphere of $\pm 5 \mathrm{~K}$ (dashed) and $\pm 20 \%$ water vapour (solid).
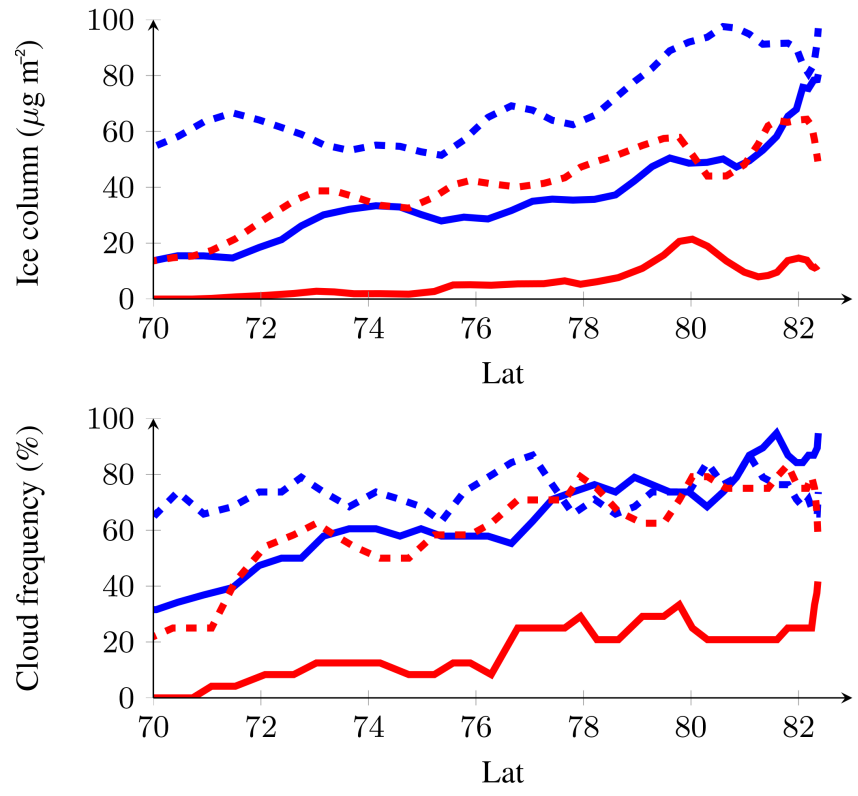

Figure 3. The latitudinal distribution of the ice column and the cloud frequency from the equilibrium model (dashed) and OSIRIS (solid) for measurements performed in July (blue) and August (red).

and SOFIE instruments could lead to differences in the results.

Considering that results from the SMR data successfully reproduce the vertical, latitudinal and seasonal variation of PMCs despite the sensitivity of the equilibrium model to errors in the background, atmospheric fields indicate that the underlying data is trustworthy. Furthermore, as will be discussed in Sect. 3.5, it may be that the high bias seen in the equilibrium model arises due to the response of PMCs to small-scale variability in the atmosphere.

\subsection{Classification of OSIRIS clouds}

As the measurements capture clouds both in growing and sublimating phases, each cloud pixel observed by OSIRIS can be classified based on the state of the background atmosphere. If there is excess water available $\left(P_{\text {gas }}>P_{\text {sat }}\right)$, the cloud is growing and thus classified as such. If the amount of ice exceeds that expected from thermodynamic equilibrium, the cloud is classified as shrinking $\left(P_{\text {gas }}<P_{\text {sat }}\right.$, but $\left.P_{\text {tot }}>P_{\text {sat }}\right)$. Finally, if the cloud is outside the region of where any ice should exist in thermodynamic equilibrium $\left(P_{\mathrm{tot}}<P_{\mathrm{sat}}\right)$ it is classified as forbidden. For this classification all detected OSIRIS clouds are included (not only those with an estimated ice mass density above the aforementioned threshold).

Figure 4 shows the result from the classification. A majority of the clouds are in a growing phase above $83 \mathrm{~km}$, while below this, a majority of the clouds are sublimating, i.e. either classified as shrinking or forbidden. Due to the general downward motion of the ice particles, this altitude, where the number of growing clouds is equal to the number of shrinking clouds, is where the maximum ice mass density is found (see Fig. 2). If only the August data is examined, the altitude where more than $50 \%$ of the clouds are sublimating is located $1 \mathrm{~km}$ higher, at $84 \mathrm{~km}$. 

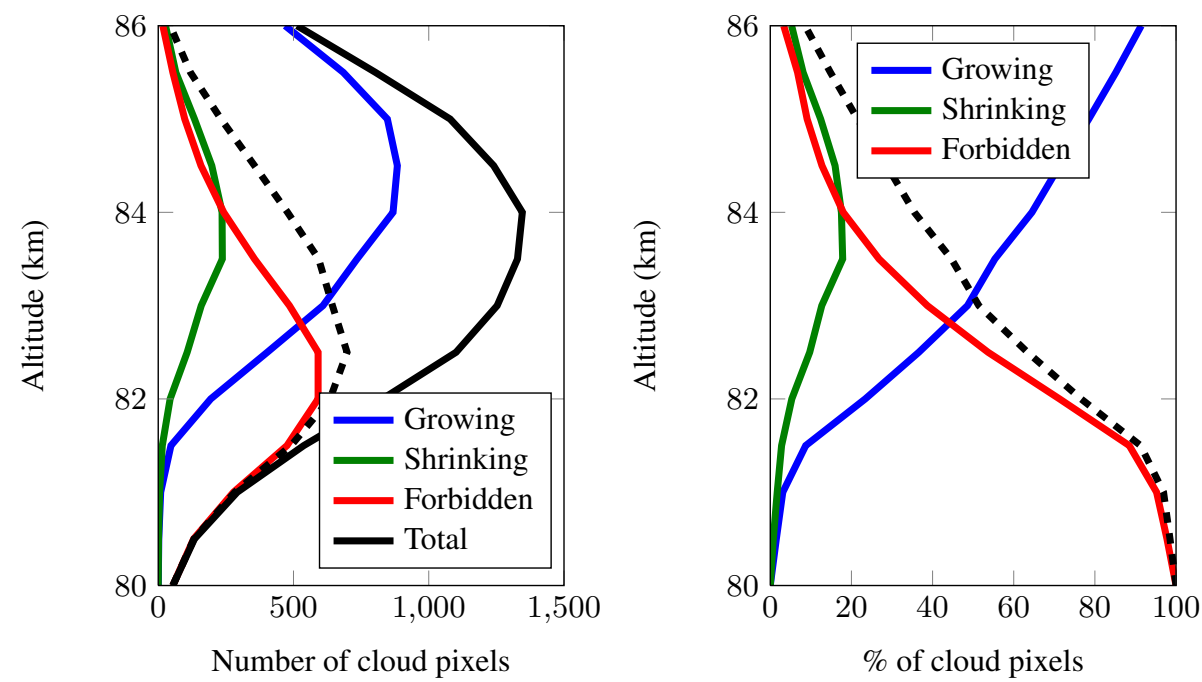

Figure 4. Classification of clouds measured by OSIRIS. The left plot shows the number of pixels measured of each type, while the right plot shows the percentage of cloud pixels in each phase. The blue lines show clouds in a growing phase, the green lines indicate that the clouds are sublimating, but that cloud presence is expected in equilibrium, and the red lines show clouds not expected in thermodynamic equilibrium. The black solid line are the total number of clouds detected, while the black dashed lines show the total number of sublimating clouds (i.e. red and green).

Below $82 \mathrm{~km}$ almost all the clouds seen are outside the region where clouds should exist if thermodynamic equilibrium is applied. Such "forbidden" clouds have been predicted by models (e.g. Megner, 2011, Fig. 7). Feofilov and Petelina (2010) and Hervig et al. (2009b) observe clouds outside the region of saturation. However, since they are unable to distinguish between clouds located in the near and far fields of the observed limb, these low-altitude clouds are filtered out of the data for being "unphysical". In total, about $50 \%$ of the clouds (254 out of 522) observed by Feofilov and Petelina (2010) are filtered out in this process. This number is comparable to our observed ratio where in total $37 \%$ of the observed clouds are outside the region allowed by thermodynamic equilibrium considerations. Unlike Hervig et al. (2009b), we do not see any significant change in the number of these clouds in the August data compared to July. This might be due to the limited data available in the tomographic data set. However, it could also depend on the fact that the altitudes where these clouds are found moves upwards with time during a season, thus fewer of these clouds would be filtered out as near- or far-field clouds in the SOFIE measurements.

\subsection{Investigation of individual clouds}

To look further at how individual measurements of clouds relate to the measured background atmosphere, the equilibrium ice mass density is compared to the measured ice mass density for each orbit separately. Figure 5 shows the measured temperature, water vapour and calculated ice mass density from the model, together with the measured ice mass density from the OSIRIS data. The three orbits are meant to illustrate some typical features seen across all the orbits measured. The abscissa is given in angle along orbit (AAO), which is the effective latitude along the orbit plane, with $\mathrm{AAO}=0^{\circ}$ at the equator and $\mathrm{AAO}=90^{\circ}$ at the northernmost position of the satellite.

The top panels show an orbit recorded on 15 July 2010. The black curve indicates the area where the supersaturation is greater than 1 , and it follows a $150 \mathrm{~K}$ contour line to a large degree, which previously has been used as a proxy for supersaturation (e.g. López-Puertas et al., 2009). The clouds measured by OSIRIS (thin contours) are mostly contained within this area. The right panel shows this in more detail with ice mass density from the equilibrium model as coloured contours and the OSIRIS values as black contours. In general there is a good agreement between the two. However, some of the internal variability seen in the measured clouds is not reproduced by the equilibrium model.

While the top panels show clouds mainly confined within the area of supersaturation, the second row shows an example where clouds are present outside the region of supersaturation, with one strong cloud located at $85^{\circ} \mathrm{AAO}$ and a thin patch at $98^{\circ} \mathrm{AAO}$. These clouds are (assuming that the retrieved water and temperature is correct) undergoing sublimation. Using Eq. (3), the sublimation time for these clouds is estimated to be less than $20 \mathrm{~min}$ for the strong cloud and $10 \mathrm{~min}$ for the thin cloud. Thus, the conditions around these clouds must have undergone a rapid change to allow detection outside the saturated region.

The lower panels show another case of clouds outside the saturated region, with cloud cover down to $80 \mathrm{~km}$ at 
Temperature $(\mathrm{K})$

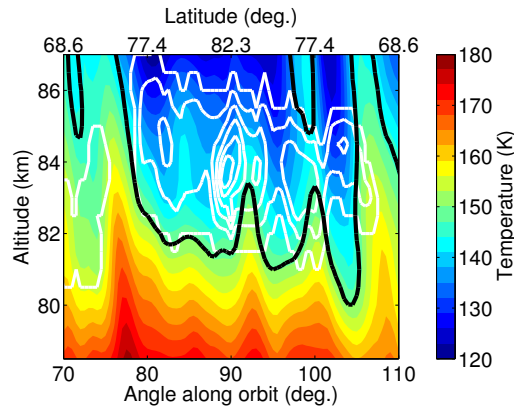

Latitude (deg.)

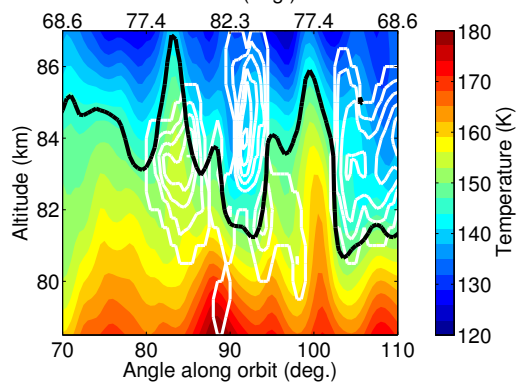

Latitude (deg.)

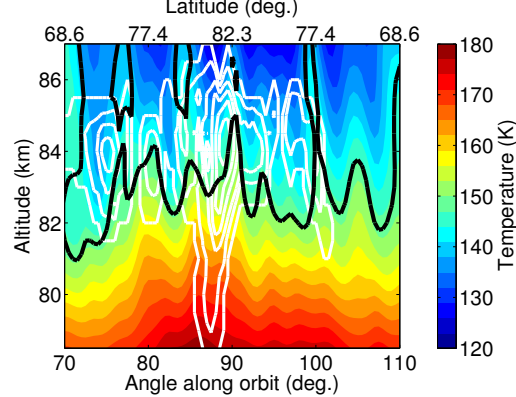

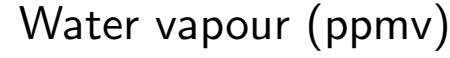

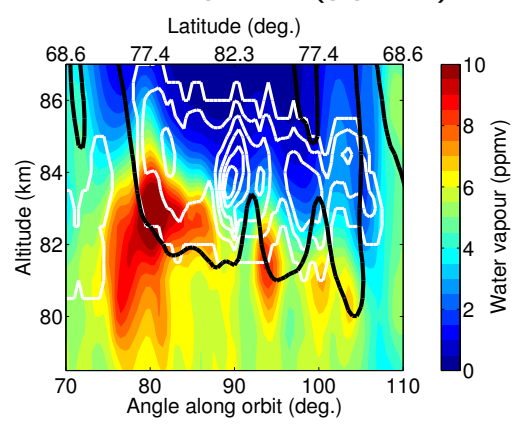
Latitude (deg.)

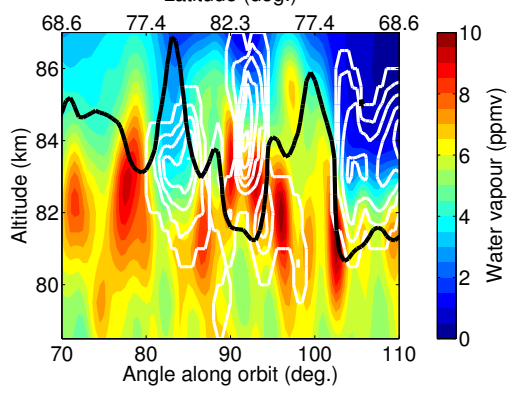

Latitude (deg.)

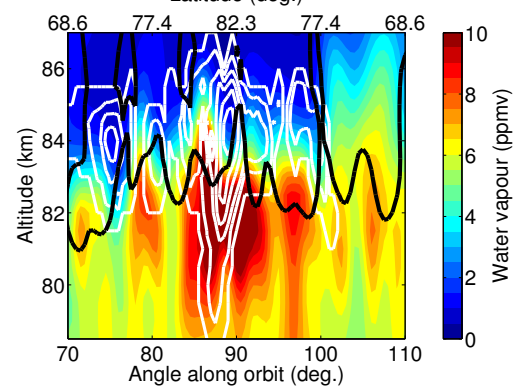

Ice mass density (ng $\mathrm{m}^{-3}$ )

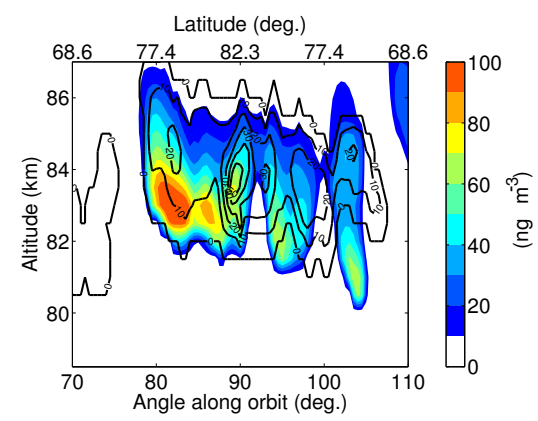

Latitude (deg.)

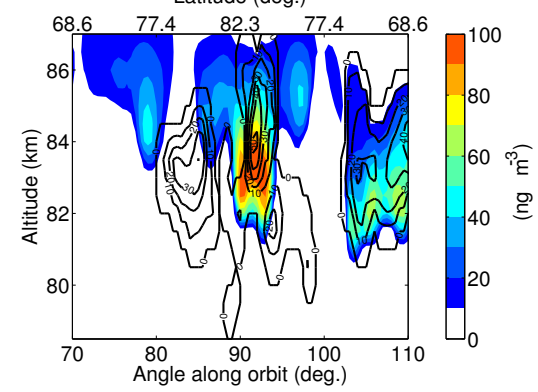

Latitude (deg.)

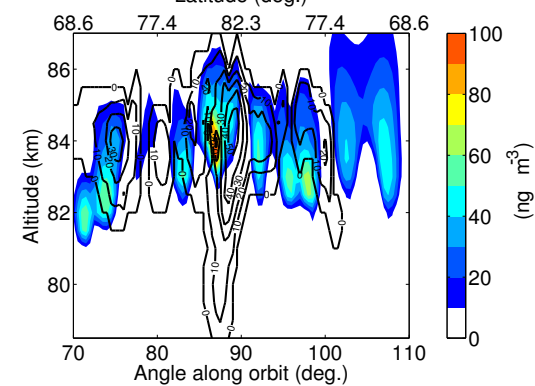

Figure 5. Three orbits measured during July 2010 (orbit 51 226, top) and 2011 (orbit 56 735, mid and orbit 56 726, bottom). The left and centre panels show the temperature and water vapour concentration retrieved from SMR (coloured contours) together with the observed ice mass density (white contours, each contour line corresponds to $10 \mathrm{ng} \mathrm{m}^{-3}$ ). The black contour shows the area where $S>1$. The rightmost plots show the ice mass density predicted by the equilibrium model (colours) and the ice mass density measured by OSIRIS (black contours, each contour line corresponds to $10 \mathrm{ng} \mathrm{m}^{-3}$ ).

$87^{\circ} \mathrm{AAO}$. These clouds were identified in Hultgren and Gumbel (2014) as regions below the typical cloud-scattering coefficient peak, with large particles ( $>80 \mathrm{~nm}$ mean radius) "raining out" of the saturated region. To refine this hypothesis, the sublimation time was calculated at different altitudes of the clouds. The resulting sublimation time is around $2 \mathrm{~h}$ at $82.5 \mathrm{~km}$, but is rapidly reduced to less than $10 \mathrm{~min}$ below $81.5 \mathrm{~km}$. Typical sedimentation speeds at $81.5 \mathrm{~km}$ for a $100 \mathrm{~nm}$ particle are on the order of $0.1 \mathrm{~m} \mathrm{~s}^{-1}$ (Turco et al., 1982), thus falling from 82 to $80 \mathrm{~km}$ would take more than $5 \mathrm{~h}$. This indicates that these vertical structures in the clouds cannot come from sedimentation alone.

Horizontal transport (zonal) of the clouds could explain these areas far below the region of supersaturation. However, due to their small sizes, ice particles tend to be transported with the air, hence staying within the same air parcel.
There is, however, a possibility for such vertical features to arise due to wind shear. If there is a strong horizontal gradient in temperature, the supersaturated region can extend to significantly lower altitudes just outside the orbital plane. If the horizontal winds are significantly smaller inside this region of supersaturation than below it, clouds sedimenting out of this region cloud be blown into the orbit plane. The result would be observed as an apparent vertical separation between the $S>1$ line and the cloud bottom, which would be larger than the true vertical separation. However, investigating orbits preceding and following these events, we do not detect any such strong horizontal gradients in temperature.

Another explanation for these structures is strong vertical winds. Indeed similar vertical cloud features have been measured by lidar (Kaifler et al., 2013) and linked to gravity waves propagating through the clouds. Kiliani et al. (2013) 
also note that ice particles can experience strong downdraughts at the lower edge of the clouds. Using the sublimation time, we estimate that the vertical transport speed needed is on the order of $1-3 \mathrm{~m} \mathrm{~s}^{-1}$, which is larger than what is suggested in Kaifler et al. (2013) and Kiliani et al. (2013) where the vertical transport speeds reported are $\sim 0.1 \mathrm{~m} \mathrm{~s}^{-1}$. Thus, if the observed cloud is due to vertical winds, it is a case with a particularly strong downdraught. Such vertical wind speeds $\left(1-5 \mathrm{~m} \mathrm{~s}^{-1}\right)$ have been observed lasting over $1 \mathrm{~h}$ in the mesopause region by ground-based very high frequency (VHF) (Rapp and Hoppe, 2006), thus we believe such winds to be a plausible cause of the observed features.

Finally, it should be mentioned that since the horizontal field of view of the two instruments differ, we cannot rule out that these low-lying clouds are caused by dynamical features resolved by SMR but not OSIRIS. But, any such feature would need to be highly localised and highly correlated in the direction of the instrument line of sight.

All three rows in Fig. 5 show areas where the equilibrium model predicts cloud presence, while no cloud is observed by OSIRIS, for example, in the area between $100^{\circ}$ and 110 $\mathrm{AAO}^{\circ}$ in the lowermost panels. Such regions are least common at the highest latitudes and at altitudes between 82 and $84 \mathrm{~km}$ in July, and most common in August, at both low latitudes and high altitudes. Once again this can be explained by temporal variations in the background atmosphere. Since growth time from a subvisible to a visible cloud is several hours (see Sect. 3.5), the ice particles will not grow into visible sizes unless these favourable conditions persist. Furthermore, as the largest ice particles sediment downward, only small, hence subvisible, particles will remain at the highest altitudes. Both these effects can lead to areas where cloud presence is predicted by thermodynamic equilibrium, but no cloud is observed. This discrepancy is also reflected in the differences in cloud presence and frequency between the equilibrium model and measurements, shown in Figs. 2 and 3.

\subsection{Discussion on the lifetime of clouds}

Since the background atmosphere of the clouds is constantly changing, the observed cloud pixels are always growing or sublimating. To determine to what degree the clouds are in equilibrium (or not) with their environment, we use the growth model described in Sect. 2.2. For each detected cloud, Eq. (3) is numerically integrated to give an indication of the temporal evolution of the detected cloud. As the initial condition, all ice particles have a radius of $5 \mathrm{~nm}$ and $Q_{\text {gas }}(t=0)=Q_{\text {tot }}-Q_{\text {ice }}^{r=5 \mathrm{~nm}}$, where $Q_{\text {ice }}^{r=5 \mathrm{~nm}}$ is the amount of water in the ice phase if the cloud consisted of $5 \mathrm{~nm}$ particles. This is scaled such that when the particles have grown to the mode radii measured by OSIRIS, the modelled $Q_{\text {ice }}$ is equal to the measured $Q_{\text {icee }}$. Figure 6 shows the hypothetical evolution of three cloud pixels from orbit 56735. The example is taken from the cloud located at $92^{\circ} \mathrm{AAO}$ at three dif-

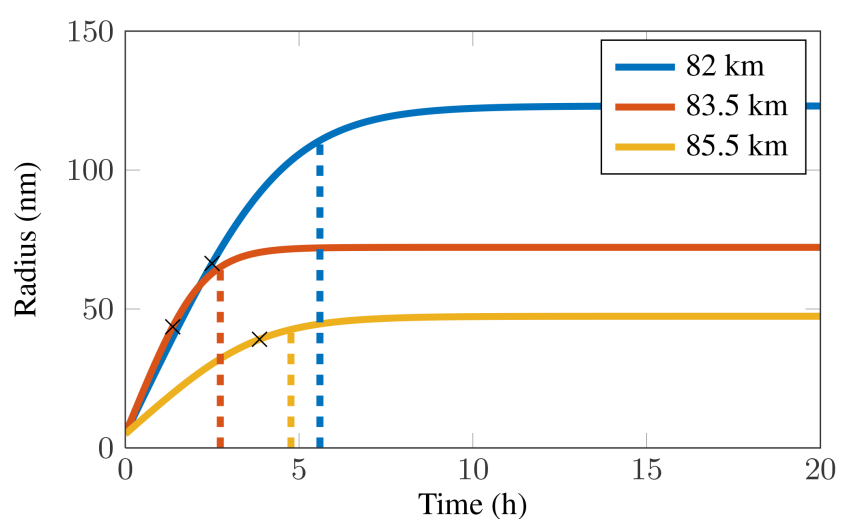

Figure 6. Ice particle growth from $5 \mathrm{~nm}$ to equilibrium for three cloud pixels at different altitudes observed at $\mathrm{AAO}=92^{\circ}$ in orbit 56735 . The black crosses indicate the measured mode radii from OSIRIS, and the vertical dashed lines show the time when the particle radius has reached $90 \%$ of the equilibrium radius.

ferent altitudes. The figure shows two growth regimes, a fast growth in the beginning due to the large amount of excess water, and a slower growth as the cloud particles asymptotically grow towards their equilibrium sizes.

The measured mode radii of the clouds are shown by the black crosses in the figure, and thus give an indication of where along the growth curve each cloud pixel is. From the figure it is clear that the equilibrium radii decrease with altitude, with equilibrium radii above $100 \mathrm{~nm}$ at the lower edge of the cloud. At the highest altitude, the time it takes for a particle to reach equilibrium is longer than in the middle of the cloud.

In order to quantify how far a given cloud pixel is from equilibrium, the time from the current radius to reaching $90 \%$ of equilibrium radius is calculated. Figure 7 shows the histograms for all detected clouds within the core cloud region $(82-84 \mathrm{~km})$ in July. It can be seen that a large portion of the cloud pixels are less than $15 \mathrm{~min}$ from equilibrium. In total, over $50 \%$ of the clouds are less than $1 \mathrm{~h}$ from equilibrium, and the mean time to equilibrium is around $2 \mathrm{~h}$. In terms of radius, most of the detected cloud pixels are between 0.6 and 1.1 times their equilibrium radius, with a median value of 0.8 . Since the volume of an ice particle scales as $r^{3}$, while the growth is approximately linear in time, this rather modest distance from equilibrium (in terms of both time and radius) can lead to large differences in the observed ice mass density.

While Fig. 7 only considers the pixels where clouds are expected according to thermodynamic equilibrium, Fig. 8 shows the time to reach equilibrium for pixels where no cloud is expected, i.e. the sublimation time. The histogram for all these forbidden pixels is shown in the left plot in Fig. 8. It can be seen that a large number of the clouds sublimate fast, and more than $50 \%$ are gone after $1.8 \mathrm{~h}$ (dashed vertical line). Thus, as discussed in Sect. 3.4, these clouds 

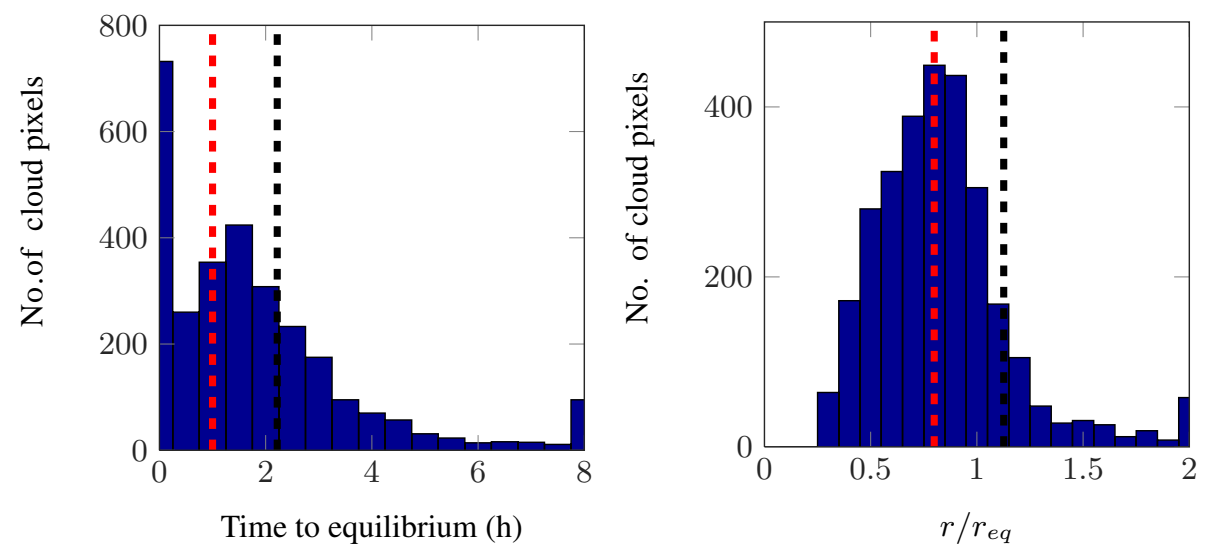

Figure 7. Left: histogram showing the time it will take for the measured pixel to reach equilibrium (not including forbidden clouds) for measurements between 82 and $84 \mathrm{~km}$ in July. Right: histogram showing the ratio between the measured mode radius and the equilibrium mode radius for the same clouds. $r / r_{\mathrm{eq}}>1$ indicates that the cloud is sublimating. The median and mean values are given by the vertical red dashed and black dashed lines respectively.
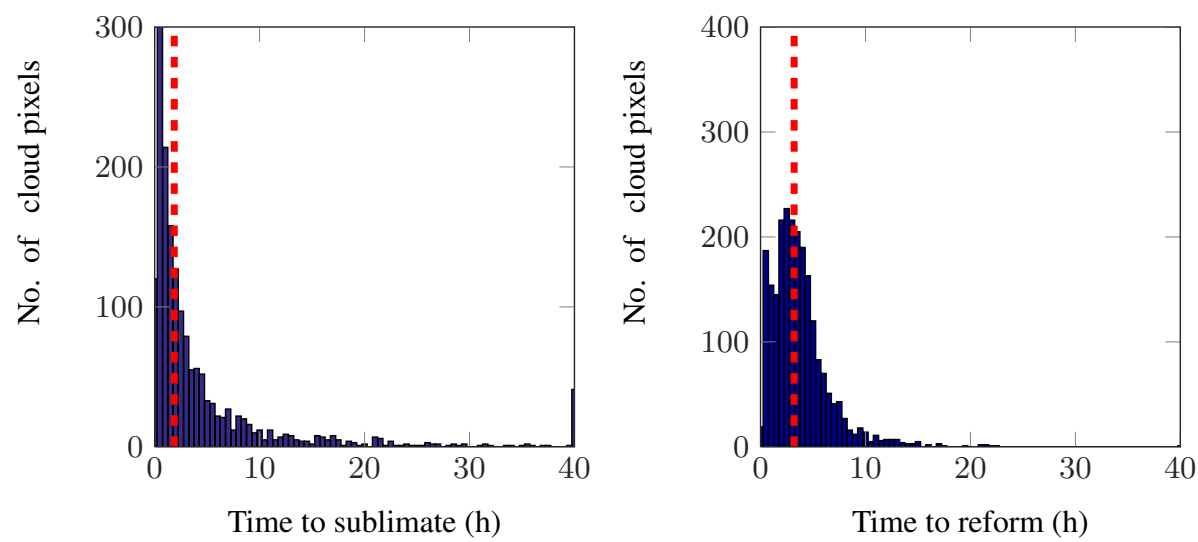

Figure 8. Left: the estimated time for forbidden clouds between 82 and $84 \mathrm{~km}$ in July to sublimate completely. Right: the estimated time for $5 \mathrm{~nm}$ particle to grow to the mode radius observed by OSIRIS. Only growing clouds between 82 and $84 \mathrm{~km}$ in July are considered. The median values are given by the vertical red dashed lines.

indicate areas where a rapid change of the background atmosphere has occurred, either through transport or temporal changes.

As the clouds seen in a sublimating phase can disappear due to atmospheric variability within hours, it is of interest to estimate the time it would take to reform these clouds. To estimate this, we look at the clouds observed in a growing phase, and calculate the time it takes for a $5 \mathrm{~nm}$ particle to grow to the measured radii. The right plot in Fig. 8 shows the time to reach the measured state for all detected growing clouds, and with a median of $3.2 \mathrm{~h}$ this is significantly longer than the median sublimation time of $1.8 \mathrm{~h}$ in Fig. 8 . This asymmetry in cloud destruction and reformation might indeed be one of the reasons for assuming that thermodynamic equilibrium overestimates the ice mass density by a factor of 2 as discussed in Sect. 3.2.

\section{Discussion and conclusions}

In this paper we have compared measurements of cloud ice mass density of polar mesospheric clouds from OdinOSIRIS with simultaneous measurements of water vapour and temperature from Odin-SMR. The comparison was done on a set of special tomographic measurements performed by Odin, and data from July 2010 and 2011, as well as August 2010, were analysed. We compared the measurements using a model assuming thermodynamic equilibrium. Consistent with previous measurements, we find that many general features of the clouds such as the altitude of maximum ice mass density, as well as the latitudinal and seasonal variation of the ice column, are reproduced by the equilibrium model.

Though many large-scale features are well represented by the equilibrium model, the model produces too much ice compared to the OSIRIS observations. This discrepancy has 
to a varying degree been reported in previous studies. In this study we suggest a possible explanation for this discrepancy. By applying a simple growth model to the clouds observed by OSIRIS, we are able to estimate the time to sublimate for the clouds in a shrinking phase, and compare this to the time it would take to grow to the clouds observed in a growing phase. The median time for sublimation in the core cloud region, at $82-84 \mathrm{~km}$ in July, was only $2.1 \mathrm{~h}$, while the expected time of regrowth was $3.2 \mathrm{~h}$. This means that temperature fluctuations on these timescales have a tendency to reduce the total ice compared to an equilibrium situation. The long reformation time also explains why many areas with high amounts of excess water are seen without the presence of PMCs.

One important factor not considered in the discussion above is that, although the median reformation time from $5 \mathrm{~nm}$ to the observed radii is $3.2 \mathrm{~h}$, this reformation time would be longer if the Kelvin effect was included. In fact, rerunning the growth model with the Kelvin effect included, we conclude that $20 \%$ (433) of the clouds included in the right plot of Fig. 8 would not even be able to reform from $5 \mathrm{~nm}$. This would further increase the depletion of ice expected from short temporal variations in the temperature.

It should be noted that these results do not imply that atmospheric variability in general leads to fewer PMCs. On the contrary, if the mean measured atmosphere is used as an input to the equilibrium model, the amount of ice predicted is significantly less than if the measured atmospheric variability is included. Our results only suggest that atmospheric variability occurring on smaller timescales than $\sim 3 \mathrm{~h}$ in the core cloud region ( $82-84 \mathrm{~km}$ in July) has a tendency to reduce the visible ice. This statement is in agreement with modelling studies. Jensen and Thomas (1994), for example, show that temperature fluctuations with periods of $1 \mathrm{~h}$ reduce the observed albedo in the modelled PMCs, and Rapp et al. (2002) conclude that short-term variations in temperature reduces visible ice, while variations on timescales larger than $6 \mathrm{~h}$ enhance PMC production.

The short sublimation $(1.8 \mathrm{~h})$ and growth times for clouds (3.2 h) shown in this study are similar to those found by Kiliani et al. (2013), who used a Langrangian cloud growth model coupled to the Leibniz-Institute Middle Atmosphere model to follow the growth and sublimation of PMCs. Their results indicate that, for clouds observed at $6^{\circ} \mathrm{N}$, most of the cloud growth occurs within $2.8 \pm 1.4 \mathrm{~h}$ of detection, and they find mean sublimation times of 1.8 to $2.8 \mathrm{~h}$ depending on latitude. From this they conclude that PMC formation is highly affected by the atmospheric conditions experienced by ice particles during the last few hours before detection. Hence, the fact that similar values are attained from the tomographic data set corroborates these conclusions, and underlines the importance of correctly describing the background atmosphere and its variability in the modelling of PMC formation.

In the data set presented we also detect forbidden clouds, far below the region of supersaturation in 5 of the 35 anal- ysed orbits. These have been seen in previous studies using limb-sounding techniques; however, due to the tomographic nature of the current measurements, we are for the first time able to distinguish the low-lying clouds from far and near field clouds. These cloud regions tend to have small number densities and consist of large particles. The estimated sublimation time for these cloud pixels are on the order of 10$30 \mathrm{~min}$, and since they are found up to $2 \mathrm{~km}$ below the region of supersaturation, it is clear that sedimentation alone cannot cause this phenomenon. We suggest that these clouds are linked to strong downdraughts. However, further investigation will be needed to verify this.

Indeed the tomographic measurements by Odin were planned such that they, as much as possible, coincide with measurements taken by the Cloud Imager and Particle Size experiment (CIPS) on board the AIM satellite. Thus, comparing the results of this study, both in terms of cloud lifetimes and cloud classification, with CIPS images captured a short time before or after the Odin measurement would help to refine and verify the conclusions drawn in this paper.

\section{Data availability}

The data and code used are available in the Supplement.

\section{The Supplement related to this article is available online at doi:10.5194/acp-16-12587-2016-supplement.}

Acknowledgements. We would like to thank Mark Hervig for providing the equilibrium model used in this study. Odin is a Swedish-led satellite project funded jointly by the Swedish National Space Board (SNSB), the Canadian Space Agency (CSA), the National Technology Agency of Finland (Tekes), the Centre National d'études Spatiales (CNES) in France and the European Space Agency (ESA).

Edited by: F.-J. Lübken

Reviewed by: two anonymous referees

\section{References}

Baumgarten, G., Fiedler, J., and Von Cossart, G.: The size of noctilucent cloud particles above ALOMAR $\left(69^{\circ} \mathrm{N}, 16^{\circ} \mathrm{E}\right)$ : Optical modeling and method description, Adv. Space. Res., 40, 772784, 2007.

Baumgarten, G., Fiedler, J., and Rapp, M.: On microphysical processes of noctilucent clouds (NLC): observations and modeling of mean and width of the particle size-distribution, Atmos. Chem. Phys., 10, 6661-6668, doi:10.5194/acp-10-6661-2010, 2010. 
Becker, E., Müllemann, A., Lübken, F.-J., Körnich, H., Hoffmann, P., and Rapp, M.: High Rossby-wave activity in austral winter 2002: Modulation of the general circulation of the MLT during the MaCWAVE/MIDAS northern summer program, Geophys. Res. Lett., 31, L24S03, doi:10.1029/2004GL019615, 2004.

Berger, U. and von Zahn, U.: Three-dimensional modeling of the trajectories of visible noctilucent cloud particles: An indication of particle nucleation well below the mesopause, J. Geophys. Res., 112, D16208, doi:10.1029/2006JD008106, 2007.

Christensen, O. M., Eriksson, P., Urban, J., Murtagh, D., Hultgren, K., and Gumbel, J.: Tomographic retrieval of water vapour and temperature around polar mesospheric clouds using OdinSMR, Atmos. Meas. Tech., 8, 1981-1999, doi:10.5194/amt-81981-2015, 2015.

Eremenko, M. N., Petelina, S. V., Zasetsky, A. Y., Karlsson, B., Rinsland, C. P., Llewellyn, E. J., and Sloan, J. J.: Shape and composition of PMC particles derived from satellite remote sensing measurements, Geophys. Res. Lett., 32, L16105, doi:10.1029/2005GL023013, 2005.

Feofilov, A. G. and Petelina, S. V.: Relation between mesospheric ice clouds, temperature, and water vapor determined from Odin/OSIRIS and TIMED/SABER data, J. Geophys. Res., 115, D18220, doi:10.1029/2009JD013619, 2010.

Gadsden, M.: Noctilucent clouds seen at $60^{\circ} \mathrm{N}$ : origin and development, J. Atmos. Sol.-Terr. Phys., 60, 1763-1772, 1998.

Hedin, A. E.: Extension of the MSIS thermosphere model into the middle and lower atmosphere, J. Geophys. Res., 96, 1159-1172, 1991.

Hervig, M., Thompson, R. E., McHugh, M., Gordley, L. L., Russell, J. M., and Summers, M. E.: First confirmation that water ice is the primary component of polar mesospheric clouds, Geophys. Res. Lett., 28, 971-974, 2001.

Hervig, M. E. and Stevens, M. H.: Interpreting the 35 year SBUV PMC record with SOFIE observations, J. Geophys. Res., 119, 12689-12705, 2014.

Hervig, M. E., Gordley, L. L., Russell, J. M., and Bailey, S. M.: SOFIE PMC observations during the northern summer of 2007, J. Atmos. Sol.-Terr. Phys., 71, 331-339, 2009a.

Hervig, M. E., Stevens, M. H., Gordley, L. L., Deaver, L. E., Russell, J. M., and Bailey, S. M.: Relationships between polar mesospheric clouds, temperature, and water vapor from Solar Occultation for Ice Experiment (SOFIE) observations, J. Geophys. Res., 114, D20203, doi:10.1029/2009JD012302, 2009b.

Hervig, M. E., Siskind, D. E., Stevens, M. H., and Deaver, L. E.: Inter-hemispheric comparison of PMCs and their environment from SOFIE observations, J. Atmos. Sol.-Terr. Phys., 104, 285298, 2013

Hervig, M. E., Siskind, D. E., Bailey, S. M., and Russell, J. M.: The influence of PMCs on water vapor and drivers behind PMC variability from SOFIE observations, J. Atmos. Sol.-Terr. Phys., 132, 124-134, 2015.

Hervig, M. E., Berger, U., and Siskind, D. E.: Decadal variability in PMCs and implications for changing temperature and water vapor in the upper mesosphere, J. Geophys. Res.-Atmos., 121, 2383-2392, 2016.

Hesstvedt, E.: Note on the nature of noctilucent clouds, J. Geophys. Res., 66, 1985-1987, 1961.

Hultgren, K. and Gumbel, J.: Tomographic and spectral views on the lifecycle of polar mesospheric clouds from Odin/OSIRIS, J.
Geophys. Res., 119, 14129-14143, doi:10.1002/2014JD022435, 2014.

Hultgren, K., Gumbel, J., Degenstein, D., Bourassa, A., Lloyd, N., and Stegman, J.: First simultaneous retrievals of horizontal and vertical structures of Polar Mesospheric Clouds from Odin/OSIRIS tomography, J. Atmos. Sol.-Terr. Phys., 104, 213 223, 2013.

Jensen, E. and Thomas, G. E.: A growth-sedimentation model of polar mesospheric clouds: Comparison with SME measurements, J. Geophys. Res., 93, 2461-2473, 1988.

Jensen, E. J. and Thomas, G. E.: Numerical simulations of the effects of gravity waves on noctilucent clouds, J. Geophys. Res. Atmos., 99, 3421-3430, 1994.

Kaifler, N., Baumgarten, G., Klekociuk, A., Alexander, S., Fiedler, J., and Lübken, F.-J.: Small scale structures of NLC observed by lidar at $69^{\circ} \mathrm{N} / 69^{\circ} \mathrm{S}$ and their possible relation to gravity waves, J. Atmos. Sol.-Terr. Phys., 104, 244-252, 2013.

Karlsson, B., Körnich, H., and Gumbel, J.: Evidence for interhemispheric stratosphere-mesosphere coupling derived from noctilucent cloud properties, Geophys. Res. Lett., 34, L16826, doi:10.1029/2007GL030282, 2007.

Karlsson, B., Randall, C., Benze, S., Mills, M., Harvey, V., Bailey, S., and Russell, J.: Intra-seasonal variability of polar mesospheric clouds due to inter-hemispheric coupling, Geophys. Res. Lett., 36, L20803, doi:10.1029/2009GL038506, 2009.

Kiliani, J., Baumgarten, G., Lübken, F.-J., Berger, U., and Hoffmann, P.: Temporal and spatial characteristics of the formation of strong noctilucent clouds, J. Atmos. Sol.-Terr. Phys., 104, 151166, 2013.

López-Puertas, M., García-Comas, M., Funke, B., BermejoPantaleón, D., Höpfner, M., Grabowski, U., Stiller, G. P., von Clarmann, T., and von Savigny, C.: Measurements of polar mesospheric clouds in infrared emission by MIPAS/ENVISAT, J. Geophys. Res., 114, D00I07, doi:10.1029/2009JD012548, 2009.

Lossow, S., Urban, J., Schmidt, H., Marsh, D., Gumbel, J., Eriksson, P., and Murtagh, D.: Wintertime water vapor in the polar upper mesosphere and lower thermosphere: First satellite observations by Odin submillimeter radiometer, J. Geophys. Res., 114, D10304, doi:10.1029/2008JD011462, 2009.

Lumpe, J., Bailey, S., Carstens, J., Randall, C., Rusch, D., Thomas, G., Nielsen, K., Jeppesen, C., McClintock, W., Merkel, A., Riesberg, L., Templeman, B., Baumgarten, G., and III, J. R.: Retrieval of polar mesospheric cloud properties from CIPS: Algorithm description, error analysis and cloud detection sensitivity, J. Atmos. Sol.-Terr. Phys., 104, 167-196, 2013.

McLinden, C. A., Fioletov, V. E., Haley, C. S., Lloyd, N., Roth, C., Degenstein, D., Bourassa, A., McElroy, C. T., and Llewellyn, E. J.: An evaluation of Odin/OSIRIS limb pointing and stratospheric ozone through comparisons with ozonesondes, Can. J. Phys., 85, 1125-1141, 2007.

Megner, L.: Minimal impact of condensation nuclei characteristics on observable Mesospheric ice properties, J. Atmos. Sol.-Terr. Phys., 73, 2184-2191, 2011.

Murphy, D. M. and Koop, T.: Review of the vapour pressures of ice and supercooled water for atmospheric applications, Q. J. Roy. Meteor. Soc., 131, 1539-1565, 2005.

Rapp, M. and Hoppe, U.-P.: A reconsideration of spectral width measurements in PMSE with EISCAT, Adv. Space. Res., 38, 2408-2412, 2006. 
Rapp, M. and Thomas, G. E.: Modeling the microphysics of mesospheric ice particles: Assessment of current capabilities and basic sensitivities, J. Atmos. Sol.-Terr. Phys., 68, 715-744, 2006.

Rapp, M., Lübken, F.-J., Müllemann, A., Thomas, G. E., and Jensen, E. J.: Small-scale temperature variations in the vicinity of NLC: Experimental and model results, J. Geophys. Res., 107, 11-20, 2002.

Rong, P., Russell, J., Hervig, M., and Bailey, S.: The roles of temperature and water vapor at different stages of the polar mesospheric cloud season, J. Geophys. Res., 117, D04208, doi:10.1029/2011JD016464, 2012.

Rong, P. P., Russell, J. M., Randall, C. E., Bailey, S. M., and Lambert, A.: Northern PMC brightness zonal variability and its correlation with temperature and water vapor, J. Geophys. Res. Atmos., 119, 2390-2408, 2014.

Russell, J. M., Rong, P., Bailey, S. M., Hervig, M. E., and Petelina, S. V.: Relationship between the summer mesopause and polar mesospheric cloud heights, J. Geophys. Res., 115, D16213, doi:10.1029/2010JD013852, 2010.

Thomas, G. E. and McKay, C. P.: On the mean particle size and water content of polar mesospheric clouds, Planet. Space Sci., 33, 1209-1224, 1985.
Thomas, G. E., Olivero, J. J., Jensen, E. J., Schroeder, W., and Toon, O. B.: Relation between increasing methane and the presence of ice clouds at the mesopause, Nature, 338, 490-492, 1989.

Turco, R., Toon, O., Whitten, R., Keesee, R., and Hollenbach, D.: Noctilucent clouds: Simulation studies of their genesis, properties and global influences, Planet. Space Sci., 30, 1147-1181, 1982.

Urban, J., Lautié, N., Murtagh, D. P., Eriksson, P., Kasai, Y., Lossow, S., Dupuy, E., Noë, J. D. L., Frisk, U., Olberg, M., Flochmoën, E. L., and Ricaud, P.: Global observations of middle atmospheric water vapour by the Odin satellite: an overview, Planet. Space Sci., 55, 1093-1102, 2007.

von Zahn, U. and Berger, U.: Persistent ice cloud in the midsummer upper mesosphere at high latitudes: Three-dimensional modeling and cloud interactions with ambient water vapor, J. Geophys. Res., 108, D88451, doi:10.1029/2002JD002409, 2003.

Zasetsky, A. Y., Petelina, S. V., Remorov, R., Boone, C. D., Bernath, P. F., and Llewellyn, E. J.: Ice particle growth in the polar summer mesosphere: Formation time and equilibrium size, Geophys. Res. Lett., 36, L15803, doi:10.1029/2009GL038727, 2009. 